\title{
What if Beethoven had been given an SSRI with a benzodiazepine chaser?
}

cambridge.org/pax

\section{Essay/Personal Reflection}

Cite this article: Wein S (2022). What if Beethoven had been given an SSRI with a benzodiazepine chaser? Palliative and Supportive Care 20, 761-763. https://doi.org/ $10.1017 /$ S1478951521000882

Received: 30 March 2021 Revised: 27 May 2021

Accepted: 30 May 2021

Author for correspondence:

Simon Wein, Pain and Palliative Care Service, Davidoff Cancer Center, Beilinson Hospital, 39 Jabotinsky Road, Petach Tikvah 4910000, Israel.

E-mail: simonwe@clalit.org.il
Simon Wein, M.D.

Pain and Palliative Care Service, Davidoff Cancer Center, Beilinson Hospital, Petach Tikvah, Israel

\section{Background}

Ludwig van Beethoven was born on 17th of December 1770 in Bonn.

In the last few months of his life, he was mortally ill from the effects of excessive alcohol consumption and arguably chronic lead toxicity. On 24th of March 1827, he said to visitors around his deathbed: "Plaudite, amici, comoedia finita est" ("Applaud, friends, the comedy is over"). Later that day when the wine arrived he whispered, "Pity - too late." He died two days later on 26th of March 1827 aged 56 in Vienna.

Beethoven first noticed difficulties with his hearing when he was about 28 years of age. By his mid-forties he was functionally deaf and unable to communicate without written notes.

\section{Heilingenstadt}

On the advice of his doctor, Beethoven moved to Heiligenstadt, then a hamlet town outside Vienna. He lived there from April to October 1802 while struggling to understand his growing deafness. It was a difficult time for the composer. In a letter to his brothers, the famous Heiligenstadt Testament (essentially a Will), he shared his intimate thoughts of life, death, and even suicide.

However, Beethoven returned to Vienna from Heiligenstadt in a rejuvenated state. He wrote to a friend that he would "seize Fate by the throat; it shall certainly not crush me completely". What changed for Beethoven?

\section{Excerpts from the Heilingenstadt Testament}

Heiligenstadt,October 61802

For my brothers Carl and [Johann]

my misfortune is doubly painful because it must lead to my being misunderstood... I must live like an exile, if I approach near to people a hot terror seizes upon me, a fear that I may be subjected to the danger of letting my condition be observed.

such incidents brought me to the verge of despair, but (a) little more and I would have put an end to my life - only Art it was that withheld me, ah it seemed impossible to leave the world until I had produced all that I felt called upon me to produce, and so I endured this wretched existence - Patience - it is said that I must now choose for my guide, I have done so, I hope my determination will remain firm to endure until it please the inexorable parcae to break the thread, perhaps I shall get better, perhaps not, I am prepared. $O$ it is not easy, less easy for the artist than for anyone else - Divine One thou lookest into my inmost soul, thou knowest it, thou knowest that love of man and desire to do good live therein.

with joy I hasten towards death - if it comes before I shall have had an opportunity to show all my artistic capacities it will still come too early for me despite my hard fate and I shall probably wish it had come later - but even then I am satisfied, will it not free me from my state of endless suffering? Come when thou will I shall meet thee bravely. - Farewell and do not wholly forget me when I am dead, I deserve this of you in having often in life thought of you how to make you happy - van Beethoven L (1802)

\section{Beethoven in 1802 age 32}

Beethoven was a virtuosic pianist with unlimited ambition and self-confidence as a composer. As a result of his deafness, he had to stop performing which had been important for fame and finances. Hence deafness would have caused a loss of self-esteem, demoralization, anger, a crisis of existence, and a depressed mood. We cannot know whether it would have qualified for a psychiatric diagnosis, such as an adjustment disorder or major depression with suicidal ideation.

Beethoven was an exuberant, eccentric, willful character with a self-absorbed mission. It is reasonable to suggest that he experienced an existential crisis with an anxiety-depression 
adjustment disorder. It does not seem likely he had a major depression since he still composed significant compositions during this period.

\section{Psychological management in 2021}

We can speculate that today many physicians would have diagnosed Beethoven with mild to moderation depression. One presumes psychotherapy would have been recommended, but how many clinicians would have prescribed antidepressants and sedatives? In Austria, in 2017, 8\% of the population used an antidepressant in the previous 12 months (Lewer et al., 2015, 221-226).

Curiously, the main side effects of Selective Serotonin Reuptake Inhibitors (SSRIs) involve the appetites: sex, gastrointestinal, emotions - the precise elements that antidepressants are designed to relieve.

SSRI-induced Indifference is a side effect of SSRIs which refers to behavior and emotions being blunted and dulled. People are emotionally less reactive and become apathetic without motivation. The prevalence is between $20 \%$ and $40 \%$ of SSRI users in various intensities (Sansone and Sansone, 2010, 14-18).

\section{What enabled Beethoven to recover?}

We do not know how he passed his time while in Heilingenstadt. We do not know if he met people. A possible clue in the Testament though is where he wrote: "Patience - it is said that I must now choose for my guide." Thus, it appears he either read something or spoke with someone and received a useful home truth.

Notwithstanding our ignorance, the following suggestions are made based on the Heilingenstadt Testament and general biographical information.

1. Friedrich Nietzsche taught that "the thought of suicide is a great consolation: by means of it one gets through many a dark night." Thinking of my death acts as a release valve. Should things become worse, then I can take my own life a paradoxical way of retaining control over ones life. There is no evidence that Beethoven made either a suicide gesture or an attempt on his life.

2. Beethoven related to his music as something extrinsic to and greater than self. Note how he wrote in the passive: "until I had produced all that I felt called upon me to produce". Beethoven felt beholden to a cause other than self which is a potent and resilient source of meaning. No time for self-pity and self-indulgence.

3. Praying and conversing with God is another way of providing perspective and self-reflection: "O Providence - grant me at least but one day of pure joy - $O$ when $-O$ when, $O$ Divine One - shall I find it again in the temple of nature and of men - Never? no - O that would be too hard." Like a prayer or psalm, asking for help from outside of self, thus avoiding self-absorption. He spent a lot of time in Nature, a recurring theme of meaning in his life.

4. Acceptance of The Fates (parcae) enabling patience, helped Beethoven to endure the unknown until the thread of life would be cut. In modern Positive Psychology theory, this might be called, forgiveness and delayed gratification.

5. Beethoven was also able to express himself with words. Writing is therapeutic. He called it philosophizing, which indeed it was, although there was a good measure of psychologizing as well.
One senses in the Testament that he is arguing with himself: convincing, preparing, hoping, compromising, back and forth, figuring life out. He clearly had insight with self-awareness.

6. Through it all Beethoven retained a positive sense of selfregard in spite of suffering: remember me after my death is a form of symbolic immortality. Musically he had at a young age a clear idea of what he could (and indeed should) achieve and ranked himself highly against all other musicians in Vienna, the capital of the music world in the early 19th century.

7. Beethoven also used irony to cope with his trials and tribulations. His penultimate recorded words were: "Applaud, friends, the comedy is over". Self-irony has two psychological prerequisites: a clear awareness of self apropos other and acknowledgment that " $\mathrm{I}$ " is of limited importance to the universe.

However, Beethoven knew he was the preeminent pianist and composer of his era so why would he laugh at himself? We might speculate that at Heilingenstadt in learned about himself, his priorities and how to cope with his impending deafness and the attendant shame, which stood him in good stead for life - and death.

Beethoven's ability to self-heal psychologically was a remarkable achievement. An early practitioner of cognitive-behavioral therapy he worked on himself psychologically and philosophically. He did not passively pop pills. Although he used alcohol, a sedative drug possibly to relieve anxiety, it did not seem to blunt Beethoven's creativity (that we know of) although it probably did shorten his life.

\section{Conclusion}

One can speculate whether psychotherapeutic medications may have adversely affected Beethoven's creativity. This historical vignette provides a useful example to consider modes of coping with ill-health.

Marcia Angell challenged this psychiatric practice: "The books by Irving Kirsch, Robert Whitaker, and Daniel Carlat are powerful indictments of the way psychiatry is now practised. They document the 'frenzy' of diagnosis, the overuse of drugs with sometimes devastating side effects, and widespread conflicts of interest. Critics of these books might argue ... that the side effects are the price that must be paid to relieve suffering caused by mental illness. If we knew that the benefits of the psychoactive drugs outweighed their harms that would be a strong argument, since there is no doubt that many people suffer grievously from mental illness. But as Kirsch, Whitaker, and Carlat argue convincingly, that expectation may be wrong.... Both psychotherapy and exercise have been shown to be as effective as drugs for depression and the effects are longer-lasting, but unfortunately, there is no industry to push these alternatives." Angell (2011a, 2011b).

Beethoven suffered - but more precisely his ability to recover from miserableness taught him resilience and coping. Listening to his music one senses that the effort expended in philosophizing and struggling benefited his composing. Beethoven's inward journey was ultimately profound. We underlings glimpse in his late string quartets a hazy reflection of the depth of the sea which he navigated.

"In accepting our limitations to control ourselves and our lives we learn humility, (a) substitute for shame, and by enduring suffering rather 
than fighting it we discover the solitary path of an inward journey." (Oreopoulos, 2005)

More than all this and that, Beethoven understood what was required to transcend his earthly limitations. He overcame his deafness yet he composed. He experienced the holiness of Nature and Providence and transcribed that to musical notes. He loved and lost. He worked long and passionately. His music is transcendent.

SSRIs, benzodiazepines, or antipsychotics could have neutered Beethoven's passion and creativity. We might ask ourselves whether we sufficiently encourage and challenge our patients to reflect, take responsibility, and self-repair in a creative search for meaning.

Or are we falling prey to the medicalization of psychological illness and the ease of popping pills?
Funding. This research received no specific grant from any funding agency, commercial or not-for-profit sectors.

\section{References}

Angell M (2011a) The epidemic of mental illness. Why? New York Times Review of Books.

Angell M (2011b) The illusion of psychiatry. New York Times Review of Books.

Lewer D, O'Reilly C, Mojtabai R, et al. (2015) Antidepressant use in 27 European countries: Associations with socio-demographic, cultural and economic factors. The British Journal of Psychiatry 207, 221-226.

Oreopoulos DG (2005) “Is there meaning in suffering?". Available at: http:// hekint.org/documents/ISTHEREMEANINGINSUFFERING.pdf

Sansone RA and Sansone LA (2010) SSRI-induced indifference. Psychiatry (Edgemont) 7(10), 14-18.

van Beethoven L (1802) Heiligenstadt Testament. Available at: https://en.wiki source.org/wiki/Heiligenstadt_Testament (accessed January 2021). 